\title{
Acute Abdomen in Fertile Women with Pain Located in the Right Iliac Fossa. Appendicitis? Observational Study
}

\section{Guillermo Padrón Arredondo*}

General Surgery of Playa del Carmen General Hospital, Av. Constituyentes s/n c/Av. 135 Suburb Ejido, Playa del Carmen, Quintana Roo. Mexico

"Corresponding Author: Guillermo Padrón Arredondo, General Surgery of Playa del Carmen General Hospital, Av. Constituyentes s/n c/Av. 135 Suburb Ejido, Playa del Carmen, Quintana Roo. Mexico, Tel: +52 1984 2061691; E-mail: hospital_2012@yahoo.com.mx

Received: 05 July 2017; Accepted: 10 July 2017; Published: 17 July 2017

\begin{abstract}
Background: Gynecological disorders related to general surgery may be considered in five themes: 1) Acute abdomen. 2) Unexpected and gynecological disorders discovered during exploratory laparotomy. 3) Pain during pregnancy. 4) Pregnancy and urinary disorders and 5) cancer of gynecological cause. Being the first two disorders which more often a general surgeon faces.
\end{abstract}

Material and Methods: In order to determine the incidence of gynecological disorders attended for genera surgeons, and iterative appendectomies resulting in cases of acute abdomen in fertile women was conducted a retrospective, observational cohort analysis over a period of 4 years in a secondary hospital under newly created with exploratory laparotomy and clinical symptoms of acute abdomen and / or probable acute appendicitis.

Results. During the study period were surgically intervened 126 women of childbearing age in our country (between 11 and 45 years of age) with acute abdomen and probable acute appendicitis of which 19 met the criteria for admission to study due to gynecoobstetric disease without acute appendicitis. There was only one case of morbidity (textiloma) and no mortality. 
Discussion. In our work we found an incidence of $15 \%$ for acute appendicitis diagnostic fails which is below international standards and is known generally from 6 to $25 \%$ of operations for acute appendicitis they reveal a normal appendix and this number rises to 30 to $40 \%$ in the case of women of childbearing

Keywords: Acute Abdomen; Appendectomy; Fertile Women; General Surgeon; Gynecologist

\section{Background}

Surgeons who began to specialize in the treatment of gynecological diseases were the first to form a separate group of general surgeons, in such a way that specialized hospitals were created in women and from there the development of their own techniques, notably by the school Of Dr. Víctor Booney, [1] where the bases of the gynecological surgery were established. However, the resulting isolation prevented brainstorming so many gynecologists are poorly trained in general surgery and general surgeons ignore gynecology.

The acute abdomen in the fertile woman may be due to the following: ectopic pregnancy, acute salpingitis, ovarian cysts (twisted, hemorrhagic, ruptured), and complicated abortions, and 2. Unexpected gynecological disorders in exploratory laparotomy such as endometriosis, tumors ovarian and uterine myomatosis [2].

It is known that abdominal pain constitutes $4 \%$ to $8 \%$ of adults admitted to hospital emergency services, of which the majority are valued by general surgeons on duty and in those with pain in the right iliac fossa the primary presumptive diagnosis is of acute appendicitis.

The inconsistency between the severity of the disease and the physical findings is greater in elderly patients and in women of reproductive age in relation to the other age groups, in addition, inconsistency increases in women fertile due to gynecological pathologies that simulate a picture of acute abdomen and acute appendicitis.

Therefore, the diagnosis and treatment of acute abdomen in these women is a challenge for general surgeons and for gynecological obstetricians.

However, the general surgeon may face some of these pathologies and intervene in circumstances where these women undergo exploratory laparotomy for acute abdomen with suspicion of acute appendicitis [3-7].

\section{Materials and Methods}

In order to know the incidence of gynecological disorders attended by general surgeons and the resulting iterative appendectomies in cases of acute abdomen in fertile women, a retrospective, observational cohort analysis was performed during a 4-year period in a second-level hospital Of new creation submitted to exploratory laparotomy with acute abdomen clinical picture and / or probable acute appendicitis. Inclusion criteria: women between 11 and 45 years of age with acute abdomen and suspicion of acute appendicitis surgically operated by exploratory laparotomy by general surgeon and with complete file. Exclusion criteria: all appendectomies performed in women younger than 11 years and older at 45 years with preoperative diagnosis of acute abdomen and / or acute appendicitis as well as female cases of all ages with preoperative diagnosis and postoperative appendicitis acute confirmed. 


\section{Results}

During the study period, 126 women (100\%) of childbearing age in our environment (between 11 and 45 years of age) were operated on for acute abdomen and probable acute appendicitis, of which 19 (15\%) met the admission criteria Study for presenting gynecologic pathology without acute appendicitis. Regarding the age of the patients, the lowest age was 11 years old and the highest age was 40 years, range of 29, mean of 24 and fashion and median of 22 years with an SD of \pm 8 years; The time of evolution of the clinical picture was 6 hours the minimum and 120 hours the maximum, with a range of 114 , the mean of 50, fashion and median of 24 and ED of \pm 40 hours; The diagnosis of admission was of 12 cases (63\%) with acute appendicitis and 7 cases (37\%) with diagnosis of acute abdomen; The vaginal touch was not performed in 13 cases (69\%), was deferred in 2 cases (10\%) and performed in 4 cases (21\%); In relation to the pregnancy test was not performed in 12 cases (64\%), did not apply in 2 cases (10\%) (for obvious pregnancy) and was performed in 5 cases (26\%), giving 3 positive and 2 negative cases For pregnancy; The hematological biometry showed a mean value of 8,000 leukocytes / mm3, maximum of 22,000 / mm3, $14.1 \mathrm{mil} /$ $\mathrm{mm} 3$ range with fashion, mean and median of $14.5 \mathrm{mil} / \mathrm{mm} 3$ and SD of \pm 4.2 leukocytes / mm3; Neutrophilia with a minimum value of $65 \%$, a maximum of $86 \%$, a range of $21 \%$, a mean of $77 \%$, a median of $79 \%$ and a fashion of $65 \%$, and an SD of $7.7 \%$ of segmented neutrophils. As diagnostic support for imaging, there were 11 abdominal ultrasounds that reported 8 cases (73\%) false-positive for acute appendicitis and 3 cases (27\%) true-negative to rule out appendicitis and in 8 cases this study was not performed. The consultation with gynecology and obstetrics was not performed in 14 cases (74\%), in 1 case it was requested and obtained, and there was joint surgical management (surgeon-gynecology) in 4 cases. The most frequent pathologies, the surgeries performed and the final diagnosis are presented in Figure 1 and Table 2, (in all cases, prophylactic appendectomy was performed, 18 for open surgery and one for laparoscopy). There was only one case with morbidity (textiloma) and there was no mortality.

\section{Discussion}

In our study we found a 15\% incidence of diagnostic failure for acute appendicitis which is within international standards since it is known that in general 6 to $25 \%$ of operations for acute appendicitis reveal a normal appendix and this number Raises up to 30 to $40 \%$ in cases of women of childbearing age where we are below the international mean for this group of patients [8-10].

The mean age in our analysis was 24 years, which is the age group with a high fertility. It is noteworthy that in the physical examination in this group, the vaginal and / or rectal touch was omitted by the general surgeon and in 13 cases it was not performed, it was deferred in two cases (patients 11 and 13 years of age) and only In four patients was performed when there was consultation with the obstetrical obstetrics service. Similarly, in relation to the pregnancy test, this is mandatory in every fertile woman with acute abdomen who goes to the emergency room, was omitted in 12 patients which may be misleading towards an evolving obstetric problem.

Regarding laboratory tests (leukocytosis with neutrophilia), they were found in agreement with what was observed in other studies and only C-reactive protein, which has proved useful in cases of intra-abdominal inflammatory processes, should be included $[11,12]$. 
Of the same the most used imaging study was the ultrasound because of its advantages of economy and availability, but it was only performed in 11 cases with a high index of diagnostic failure due to the equipment-operator dependence, which makes it of limited value in these cases, likewise, this study was not performed in 8 cases. Currently modern medicine depends on laboratory analysis and imaging results, hence the merit of physical examination has declined but in cases of acute abdomen the technology can't replace the experience and clinical judgment of the surgeon through of a good anamnesis and the complete physical examination.

The utility of imaging is beyond doubt to both ultrasound (the most accessible), tomography and magnetic resonance, especially when there is an overlapping of symptoms between gastrointestinal and gyneco-obstetric conditions and are very useful in cases of diagnostic doubt. Similarly, the combination of transvaginal ultrasound with abdominal ultrasound is very useful in these cases, usually in the hands of the obstetrician.

It is noteworthy the lack of consultations with the obstetrics and gynecology department, since in our study in 14 cases (74\%), it was not requested by the emergency department or the general surgeon, and only in one case was it requested and obtained. However, there were 4 cases where there was interaction between both services during the diagnosis and treatment of cases with acute abdomen that was also negative for acute appendicitis. Therefore, in our series 12 cases were admitted to the operating room with a diagnosis of acute appendicitis and 7 cases with a diagnosis of acute abdomen.

The resolution of these cases of acute abdomen was by laparotomy in 18 cases and by laparoscopy one case (pediatric), however, currently with the generalization of laparoscopic surgery it is advisable to make more liberal use of this technique, especially in cases of diagnostic doubt and availability of the resource $[17,18]$.

The gynecologic pathology found is consistent with that found in the literature and general surgeons should be able to resolve them if they do not have a gynecologist and in other cases to work together with them for the complete resolution of acute abdominal pictures in this population group.

Regardless of the pathology found and resolved, in all cases of our study, it was performed an iterative appendectomy, a controversial behavior, but it was performed in cases of acute abdomen with exploratory laparotomy with a healthy appendix in our institution [19, 20]. Finally, in this review, the morbidity index was minimal although the only case was significant (textiloma, resolved at another institution a month later).

\section{Conclusions}

1. In this study found a $15 \%$ incidence of diagnostic failure for acute appendicitis in women of childbearing age, which is below international standards, as this number rises to 30 to $40 \%$ and is in line with that percentage of failure in the general population for the same diagnosis.

2. General surgeons should be trained to solve basic gynecological and obstetric disorders found during an exploratory laparotomy and do not have an OB / GYN.

3. Interconsultation with the gynecoobstetric is mandatory in this population group because diagnosis failure is possible and collaboration between both occasional specialties. 


\section{Conflict of interest}

None.

\section{Ethical approval}

None for being a retrospective study.

\section{Financial support}

None

\section{References}

1. Philipp EE. Victor Bonney: The Gynecological Surgeon of the Twentieth Century. J R Soc Med 94 (2001): 311-312.

2. Cameron M. Gynecology and general Surgery. Ann Royal Coll Surg Engl 56 (1975): 115-123.

3. Hatipoglu S, Hatipoglu F, Abdullayev R. Acute right lower abdominal pain in women of reproductive age: clinical clues. World J Gastroenterol 20 (2014): 4043-4049.

4. Howell JM, Eddy OL, Lukens TW, Thiessen ME, Weingart SD, Decker WW. Clinical policy: critical issues in the evaluation and management of emergency department patients with suspected appendicitis. Ann Emerg Med 55 (2010): 71-116.

5. Wray CJ, Kao LS, Millas SG, Tsao K, Ko TC. Acute appendicitis: controversies in diagnosis and management. Curr Probl Surg 50 (2013): 54-86.

6. Ma KW, Chia NH, Yeung HW, Cheung MT. If not appendicitis, then what else can it be? A retrospective review of 1492 appendectomies. Hon Kong Med J 16 (2010): 12-17.

7. Evsen MS, Soydinc HE. Emergent gynecological operations: a report of 105 cases. J Clin Exp Invest 1 (2010): 12-15.

8. Paulson EK, Kalady MF, Pappas TN. Clinical practice. Suspected appendicitis. New Engl J Med 348 (2003): 236-242.

9. Flum DR, Koepsell T. The clinical and economic correlates of misdiagnosed appendicitis: nationwide analysis. Arch Surg 137 (2002): 799-804.

10. Singhal V, Jadhav V. Acute appendicitis: are we over diagnosing it? Am R Coll Surg Engl 89 (2007): 766769.

11. Dueholm S, Bagi P, Bud M. Laboratory aid in the diagnosis of acute appendicitis. A blinded, prospective trial concerning diagnostic value of leukocyte count, neutrophil differential count, and $\mathrm{C}$ reactive protein. Dis Colon Rectum 32 (1989): 855-859.

12. Yang HR, Wang YC, Chung PK, Chen WK, Jeng LB, Chen RJ. Laboratory tests in patients with acute appendicitis. ANZ J Surg 76 (2006): 71-74.

13. Roche O, Chavan N, Aquilina J, Rockall A. Radiological appearances of gynaecological emergencies. Insights Imaging 3 (2012): 265-275.

14. Mazzei MA, Guerrini S, Squitieri NC, Cagini L, Macarini L,Coppolino F, et al. The role US examination in the management of acute abdomen. Crit Ultrasound J 5 (2013): 56: 1-9. 
15. Tabbara M, Evangelopoulos N, Raio L, Banz V, Zimmerman H, Kim-Fuchs C, et al. Transvaginal ultrasound in fertile patients with suspected appendicitis: an experience report of current practice. Emerg Med Int 2012: 1-5.

16. Bondi M, Miller R, Zbar A, Hazan Y, Appelman Z, Caspi B, et al. Improving the diagnostic accuracy of Ultrasonography in suspected acute appendicitis by combined transabdominal and transvaginal approach. Am Surg 78 (2012): 98-103.

17. Larsson PG, Henriksson G, Olsson M, Boris J, Stroberg P, Tronstad SE, et al. Laparoscopy reduces unnecessary appendicectomies and improve diagnosis in fertile woman. A randomized study. Surg Endosc 15 (2001):200-202.

18. Navarrete-Aulestia S, Cantele H, Leyba JL, Navarrete M, Navarrete-Llopla S. Laparoscopic diagnosis and treatment in gynecologic emergencies. J Soc Laparoendosc Surg 7 (2003): 239-242.

19. van den Broek WT, Bijnen AB, de Ruiter P, Gouma DJ. A normal appendix found during diagnostic laparoscopy should not be removed. Br J Surg 88 (2001): 251-254.

20. Khairy G. Acute apendicitis: is removal of a normal appendix still existing and can we reduce its rate? Saudi J Gastroenterol 15 (2009): 167-70.

This article is an open access article distributed under the terms and conditions of the

Creative Commons Attribution (CC-BY) license 4.0 